\title{
Survey of human and bovine tuberculosis infection on dairy farms in southwestern China
}

\section{Shu Zhang ( $\square$ dulianyouchao@qq.com )}

Sichuan Center for Disease Control and Prevention https://orcid.org/0000-0001-6123-5418

\section{Chuang Chen}

Sichuan Center for Disease Control and Prevention, Chengdu, Sichuan, China.

\section{Zhengyuan Rao}

Sichuan Center for Disease Control and Prevention, Chengdu, Sichuan, China.

\section{Aiguo Yang}

Sichuan Animal Epidemic Prevention and Control Center, Chengdu, Sichuan, China.

\section{Li Guo}

Sichuan Animal Epidemic Prevention and Control Center, Chengdu, Sichuan, China.

\section{Wei Hou}

Sichuan Animal Epidemic Prevention and Control Center, Chengdu, Sichuan, China.

\section{Liang Zhang}

Hongya Center for Disease Control and Prevention, Hongya County, Meishan, Sichuan, China.

\section{Xiulan Yang}

Hongya Center for Disease Control and Prevention, Hongya County, Meishan, Sichuan, China.

\section{Yan Liu}

Hongya Center for Animal Epidemic Prevention and Control, Hongya County, Meishan, Sichuan, China.

\section{Yumei Wu}

Hongya Center for Animal Epidemic Prevention and Control, Hongya County, Meishan, Sichuan, China.

\section{Research article}

Keywords: Zoonotic disease; Nontuberculous Mycobacteria; Susceptibility; Bovine

Posted Date: February 28th, 2020

DOI: https://doi.org/10.21203/rs.2.16233/v2

License: (1) This work is licensed under a Creative Commons Attribution 4.0 International License. Read Full License 


\section{Abstract}

Background: Tuberculosis is a zoonotic chronic infectious disease caused by Mycobacterium tuberculosis complex (MTBC) that can be transmitted between humans and cattle. The aim of our study was to identify cross-infections of MTBC between humans and cattle on dairy farms in Sichuan Province, southwestern China. Results: We selected 6 large-scale and 5 small-scale dairy farms in Sichuan Province as research sites. A total of 378 dairy farm workers (except one pregnant woman) were screened for tuberculosis symptoms and examined by X-ray. One worker was diagnosed as tuberculosis, though the sputum culture was negative. In total, 99 of 10,224 (0.97\%) cows showed positive results for the purified protein derivative (PPD) skin tests. Esophageal-pharyngeal (OP) secretions from PPD-positive cows were cultured and 21 isolates were obtained. Sequences of 16s rDNA, hsp65 and rpoB and 16s-23s rRNA spacer region were amplified and sequenced. BLAST analysis classified these isolates as nontuberculous mycobacteria (NTM) (18 M. nonchromogenicum, $1 \mathrm{M}$. hiberniae, $1 \mathrm{M}$. arupense, and $1 \mathrm{M}$. chitae isolates). Conclusion: This study indicates that the PPD-positive cows in these dairy farms were infected with NTM rather than MTBC. Tuberculosis cross-infection between humans and cows on dairy farms has been well controlled in this region.

\section{Background}

Tuberculosis is a chronic zoonotic disease caused by the Mycobacterium tuberculosis complex(MTBC), which includes $M$. tuberculosis, $M$. bovis, $M$. africanum, M. pinnipedii, M. microti, M. caprae, M. canetti, M. mungi, $M$. orygis. It mainly infects respiratory tract, digestive tract (food and milk with bacteria), and a low percentage of skin wounds. Humans are susceptible to $M$. tuberculosis and $M$. bovis [1]. Cattles are considered as a natural reservoir for $M$. bovis [1], and infection caused by $M$. tuberculosis [2,3] and $M$. caprae[4,5] in cattle were reported. The other members of MTBC could also cause tuberculosis in human and/or other animals, but are seldom found in bovine. Transmission of $M$. tuberculosis complex (mostly M. tuberculosis and $M$. bovis) between human and cattle are reported[6-8] .

As stated in previous reports, the infection status of bovine tuberculosis is seriously, especially dairy cows are most susceptible bovines to tuberculosis[9]. Dairy cows can transmit tuberculosis to workers through respiratory secretions and feces. Milk secreted by cows with tuberculosis and dairy products that do not undergo pasteurization can also transmit tuberculosis to humans[10-11]. Approximately $3 \%$ of tuberculosis patients become infected with $M$. bovis by consuming unsterilized milk or dairy products[1213], and slaughterhouse workers may also be infected by infected tissue[14]. In Asian and African, 4.7\% to $30.8 \%$ of tuberculosis-positive cattle are infected with human $M$. tuberculosis strain [15]. Moreover, prevalence of human tuberculosis will rise when the proportion of cattle infected with human tuberculosis bacteria increases on a given farm[16]. According to reports from 2010, the prevalence of bovine tuberculosis in China was $0-15 \%[17]$. Some researches indicate simultaneous infection of MTBC in humans and cattle[1,7,18].Therefore, we conducted a survey of tuberculosis among cows and workers in large and small dairy farms in Sichuan Province, southwestern China, aiming to evaluate cross infections of MTBC between bovines and humans. 


\section{Results}

\section{Population survey}

A total of 378 workers from 5 large-scale dairy farms and 6 small-scale dairy farms were screened for symptoms; 377(a pregnant woman was not included) were examined by chest X-ray (DR). Based on the symptom screening results, all workers were asymptomatic; 1 person had an abnormal chest $\mathrm{X}$-ray result with suspected tuberculosis lesions. Sputum samples collected from 5 workers (one pregnant woman; one abnormal chest X-ray person; three slight cough persons) were subjected to sputum smear and culture, and all samples showed negative results. One patient with abnormal chest X-ray result was clinically diagnosed and referred for tuberculosis management and treatment.

\section{Investigation of dairy cows}

A total of 10,224 cows were examined by PPD skin tests. Ninety-nine cows were PPD positive, but none of them displayed suspicious symptoms. Esophageal-pharyngeal (OP) secretions of the 99 PPD-positive cows were cultured on acid LJ medium, 21 bacteria isolations were obtained from these samples. OP secretions from 88 PPD-negative cows and 20 environmental samples that were adjacent to PPD-positive cows were also cultured, and all samples showed negative results.

\section{Identification of species}

The sequences of the $16 \mathrm{~S}$ rDNA, $h s p 65$, and $r p o B$ genes and ITS region were sequenced to identify species by multilocus sequence analysis. The species of the 21 strains are presented in Table 1 . All of the strains were nontuberculous mycobacteria (NTM).

\section{Drug sensitivity testing results}

Antimicrobial susceptibility testing results for the 20 isolates(Mycobacterium arupense did not grow)from the PPD-positive cows are shown in Table 2.

\section{Discussion}

The tuberculosis epidemic in China is high; however, it is not as severe as those in India and Indonesia. Sichuan Province is a populous province in southwestern China, and the epidemic of tuberculosis in this province is very concerning. In addition, many dairy cows raised in Sichuan Province. Tuberculosis is a zoonotic infectious disease caused by MTBC. Previous reports have shown evidence of tuberculosis cross infection between humans and cattle[1,2,6,8]. 
We screened dairy farm workers for tuberculosis symptoms and performed chest X-ray; all cows were screened by PPD skin tests. OP secretions were obtained from PPD-positive cattle, and the cows were fasted for 12 hours (with water accessible) to ensure that the OP secretions were not contaminated by ruminate. The results of the environmental sample cultures for the PPD-positive cattle were negative. Culture was also used to verify that the samples from OP secretions were not contaminated by environmental mycobacteria.

According to previous Chinese reports, the infection rate of MTBC in cows on dairy farms in China is $1 \%$ by the PPD methods. In our study, the PPD-positive rate was approximately $1 \%$,too, which is consistent with previous reports. Through the culture of OP secretions from PPD-positive cows, 21 isolates were obtained; however, these isolates were classified as NTM after $16 S$ rDNA, hsp65, rpoB gene and ITS region sequencing and alignment. This finding indicates that there may be an error in the $1 \%$ MTBC infection rate reported in the previous paper mentioned above, as these cows were likely infected with NTM. According to our current data, tuberculosis in dairy cows has been well controlled, and NTM is the most likely infection source in PPD-positive cows. So, it is important to confirm the true MTBC infection rate of dairy cows in China by culture and PCR.

In this study, 21 NTM strains(18 M.nonchromogenicum, 1 M.hiberniae, 1 M.arupense, and 1 M.chitae) were isolated. A study from Northern Ireland also reported culture of M. nonchromogenicum (a member of the $M$. terrae complex, a nonpigmented, slow-growing species) from cattle, indicating that $M$. nonchromogenicum is a dominant mycobacterium among cattle strains[22]. In previous studies, $M$. nonchromogenicum, M.hiberniae, and M.arupense were also found to be responsible for human infection and disease[23-27]. The minimum inhibitory concentrations (MICs) of 21 types of drugs against $M$. nonchromogenicum, $M$. hiberniae and $M$. arupense were relatively high in the drug sensitivity test; in contrast, the M. chitae MIC was low. Therefore, it is difficult to select appropriate drugs for the treatment of these NTM. Therefore, these NTM MICs will provide some guidance for future research. We believe that our study makes a significant contribution to the literature because it is the first to identify infection with NTM but not MTBC in PPD-positive dairy cows in southwestern China.

\section{Conclusions}

Our study indicates that the PPD-positive rate of cows on dairy farms in Sichuan Province, which is located in southwestern China, was approximately $10 \%$, but these cows were infected with NTM rather than Mycobacterium bovis or Mycobacterium tuberculosis. Crossinfection of MTBC between humans and cows on dairy farms has been controlled.

\section{Methods}

Research sites 
The study sites were in Hongya County, Sichuan Province, southwestern China. All dairy farms in this county were in this survey, including five large-scale dairy farms and six small-scale dairy farms.

\section{Investigation methods}

All the staff at the investigation sites were screened for clinical symptoms (coughing lasts two or more weeks, coughing up blood, chest pain, unintentional weight loss, Fatigue, Fever, night sweats, chills, loss of appetite) and examined by chest X-ray (DR). Sputum smears (night sputum, morning sputum and spot sputum) and sputum cultures were performed for those with suspected tuberculosis symptoms and suspected tuberculosis on chest X-ray.

All dairy cows at the survey sites were screened by single intradermal cervical comparative test (SICCT) using purified protein derivative (PPD) of Mycobacterium bovis tuberculin(purchased from Zhongmu CO., LTD., Chengdu, China). The cows were inoculated with $0.1 \mathrm{ml}$ of bovine PPD in the position of anterior neck, the results were computed as the difference in skin fold thickness in millimeters $(\mathrm{mm})$ before and $72( \pm 4)$ hours after injection of the bovine PPD. The skin fold thickness increased $4 \mathrm{~mm}$ or more, or severe local clinical signs(pain, edema, necrosis, exudation, emphysema, swelling, and/or local lymph node hypertrophy) were observed, it was considered the reactor to be positive.

Esophageal-pharyngeal (OP) secretions obtained from dairy cows (PPD-positive cows, cows with suspected tuberculosis symptoms, and adjacent cows of PPD-positive cows) that were fasted (water was provided) for 12 hours were cultured; environmental samples of PPD-positive cows were collected for culture as well.

\section{Culture and DNA extraction}

After treatment with $4 \% \mathrm{NaOH}$, acid Löwenstein-Jensen (LJ) medium (purchased from Celnovte, CO., LTD., Zhengzhou, China) was used to culture the samples. Each sample was cultured in two tubes at $37^{\circ} \mathrm{C}$ for 1-2 months.

DNA was extracted from the cultured strains by the heating method. The culture strains were suspended in $100 \mu \mathrm{l}$ of sterile distilled water and heated at $99^{\circ} \mathrm{C}$ in a heating block for $20 \mathrm{~min}$. The DNA obtained was stored at $-20^{\circ} \mathrm{C}$.

Amplification and sequencing of the16S rDNA, hsp65, and rpoB genes and ITS region

Primers were designed to amplify the $16 S \mathrm{rDNA}$, $h s p 65$, and $r p o B$ genes and internal transcribed spacer (ITS) region to accurately identify Mycobacterium strains,vaccording to previous reports[19-21]. 
To amplify the $16 S$ rDNA of Mycobacterium, the following primers were used: $16 \mathrm{~S}-\mathrm{F}\left(5^{\prime}-\right.$ AGAGTTTGATCCTGGCTCAG-3') and 16S-R(5'-AAGGAGGTGATCCAGCCGCA-3'). Two microliters of culture-suspended DNA was used as the DNA template in a 50- $\mu$ l PCR mixture containing $25 \mu$ of $2 *$ Taq Master Mix (purchased from Cwbiotech, CO., LTD., China), $1 \mu$ l of each forward and reverse primer (10 $\mathrm{pmol} / \mathrm{l}$ ) and $21 \mu \mathrm{l}$ of double-distilled water. The PCR cycling parameters were as follows: $95^{\circ} \mathrm{C}$ for $5 \mathrm{~min}$ for initial denaturation; followed by 35 cycles of denaturation for $1 \mathrm{~min}$ at $95^{\circ} \mathrm{C}$, annealing for $1 \mathrm{~min}$ at $58^{\circ} \mathrm{C}$, and elongation for $1 \mathrm{~min}$ at $72^{\circ} \mathrm{C}$; and a final extension at $72^{\circ} \mathrm{C}$ for $10 \mathrm{~min}$.

hsp65PCR

The primers hsp65-F(5'-ATCGCCAAGGAGATCGAGCT-3') and hsp65-R(5'-AAGGTGCCGCGGATCTTGTT-3') were used to amplify the $h s p 65$ gene. The 50- $\mu$ l PCR mixture contained $21 \mu$ l of double-distilled water, 25 $\mu$ l of 2*Taq Master Mix (purchased from Cwbiotech, CO., LTD.,China), $1 \mu$ l of each forward and reverse primer $(10 \mathrm{pmol} / \mathrm{I})$, and $2 \mu \mathrm{l}$ of DNA template. The PCR cycling parameters were as follows: initial denaturation at $95^{\circ} \mathrm{C}$ for $5 \mathrm{~min}$; followed by 35 cycles of denaturation for $1 \mathrm{~min}$ at $95^{\circ} \mathrm{C}$, annealing for 1 min at $63^{\circ} \mathrm{C}$, and elongation for $1 \mathrm{~min}$ at $72^{\circ} \mathrm{C}$; and a final extension at $72^{\circ} \mathrm{C}$ for $10 \mathrm{~min}$.

rpoBPCR

rpob-F(5'-GGCAAGGTCACCCCGAAGGG-3') and rpob-R(5'-AGCGGCTGCTGGGTGATCATC-3') were used for

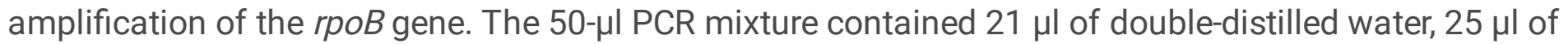
2*Taq Master Mix (purchased from Cwbiotech, CO., LTD., China), $1 \mu$ l of each forward and reverse primer (10 pmol/l), and $2 \mu \mathrm{l}$ of DNA template from the culture suspensions. The PCR cycling parameters were as follows: initial denaturation at $95^{\circ} \mathrm{C}$ for $5 \mathrm{~min}$; followed by 35 cycles of denaturation for $1 \mathrm{~min}$ at $95^{\circ} \mathrm{C}$, annealing for $1 \mathrm{~min}$ at $60^{\circ} \mathrm{C}$, and elongation for $1 \mathrm{~min}$ at $72^{\circ} \mathrm{C}$; and a final extension at $72^{\circ} \mathrm{C}$ for $10 \mathrm{~min}$.

16S rDNA-23S rDNA internal transcribed spacer(ITS) PCR

ITS-F(5'-AAGTCGTAACAAGGTARCCG-3') and ITS-R(5'-TCGCCAAGGCATCCACC-3') were used for amplification of the ITS gene fragment. The50- $\mu$ I PCR mixture contained $21 \mu$ l of double distilled water, $25 \mu$ l of 2*Taq Master Mix (purchased from Cwbiotech, CO., LTD., China), $1 \mu$ l of each forward and reverse primer (10 pmol/I), and $2 \mu \mathrm{l}$ of DNA of the culture suspensions. The PCR cycling parameters were as follows: initial denaturation at $95^{\circ} \mathrm{C}$ for $5 \mathrm{~min}$; followed by 35 cycles of denaturation for $1 \mathrm{~min}$ at $95^{\circ} \mathrm{C}$,annealing for $1 \mathrm{~min}$ at $60^{\circ} \mathrm{C}$, and elongation for $1 \mathrm{~min}$ at $72^{\circ} \mathrm{C}$; and a final extension at $72^{\circ} \mathrm{C}$ for 10 $\min$.

Sequencing of $16 \mathrm{~S}$ rDNA, hsp65, and rpoB genes and the ITS region amplification products 
Gene amplification products of the 16S rDNA, hsp65, and $r p o B$ genes and the ITS region were sequenced by Tsingke (Beijing, China).

Alignment of sequences and identification of species

The sequences of the amplified products (16S rDNA, hsp65, rpoB and ITS) were analyzed using the NCBI BLAST platform (https://blast.ncbi.nlm.nih.gov/Blast.cgi) with MegaBLAST for species identification.

\section{Drug sensitivity tests}

The in vitro drug susceptibility of the strains was evaluated by the broth dilution method according to the guidelines of the Clinical and Laboratory Standards Institute (CLSI).

\section{List Of Abbreviations}

MTBC: Mycobacterium tuberculosis complex; PPD: purified protein derivative; OP: esophagealPharyngeal; NTM: nontuberculous mycobacteria; $h s p 65$ : heat shock protein $65 ;$ rpoB: $\beta$ subunit of bacterial RNA polymerase; ITS. 16S rDNA-23S rDNA internal transcribed spacer

\section{Declarations}

\section{Ethics approval and consent to participate}

This study was authorized by the Sichuan Center for Disease Control and Prevention and the Sichuan Medical Association. Ethical approval was obtained from the Research Ethics Committee of Sichuan Center for Disease Control and Prevention. The animals in this study were taken for routine diagnostics and not used for experimental studies, and the material consisting of esophageal-pharyngeal secretions (OP secretions) used in this study was collected by local vets after verbal approval from the owners for further research. All the staff involved in this study gave oral informed consent. According to the review of biomedical research ethics (SC/DL-GZ023) of Sichuan Centers for Disease Control and Prevention, collecting animal sputum culture isolates does not require ethical review. We drafted written informed consent for the participants, but the owners of the dairy farms believed that oral consent was faster and more convenient and supported oral consent. As the ethical review committee agreed to this practice (Sichuan CDC ethical committee ethical review 4.7: Oral informed consent is allowed when signature would bring trouble to someone), we obtained oral informed consent.

\section{Consent for publication}

Not applicable. 
Availability of data and materials

All data supporting the results of this paper are included in this published article.

\section{Competing interests}

The authors declare that they have no competing interests.

\section{Funding}

This study was funded by the Sichuan Medical Association(Grant No. S16066).

\section{Author contributions}

Chuang Chen supervised the project. Zhengyuan Rao, Aiguo Yang, Li Guo, Wei Hou, Liang Zhang, XiulanYang, YanLiu, YumeiWu and Shu Zhang participated in the field investigation. Chuang Chen and Shu Zhang completed the lab work. Shu Zhang drafted and revised the manuscript. All authors read and approved the final manuscript.

\section{References}

1. LoBue PA, Enarson DA, Thoen CO. Tuberculosis in humans and animals: an overview. Int. J. Tuberc. Lung Dis. 2010;14(9):1075-1078.

2. Ocepek M, Pate $M$, Žolnir-Dovč $M$, et al. Transmission of Mycobacterium tuberculosis from human to cattle. J Clin Microbiol. 2005; 43:3555-3557.

3. Du Y, Qi Y, Yu L, Lin J, Liu S, Ni H, Pang H, Liu H, Si W, Zhao H, Wang C. Molecular characterization of Mycobacterium tuberculosis complex (MTBC) isolated from cattle in northeast and northwest China. Res Vet Sci. 2011; 90:385e91.

4. Valcheva V,Savova-Lalkovska T, Vyazovaya A, Dimitrova A, Bonovska M, Najdenski H. First insight into phylogeography of Mycobacterium bovis and M. caprae from cattle in Bulgaria. Infect Genet Evol. 2020. https://doi.org/10.1016/j.meegid.2020.104240.

5. Amato L, Mulatti P, Pacciarini M, Schiavon E, Zanoni M, Bonfanti L. Mycobacterium caprae in a dairy farm in Northeast Italy. Vet Ital. 2019; 55(4). https://doi.org/10.12834/Vetlt.1350.7441.2.

6. Cadmus S, Akinseye VO, van Soolingen D. Mycobacterium bovis in humans and in animals in Nigeria: an overview from 1975-2014. Int J Tuberc Lung Dis. 2019;23(11). https://doi.org/10.5588/ijtld.18.0641.

7. AmeniGK, Tadesse E, Hailu Y, et al. Transmission of Mycobacterium tuberculosis between farmers and cattle in Ethiopia. PLoS ONE. 2013;8(Suppl 10):e76891.

8. Olea-Popelka F, Muwonge A, Perera A, Dean AS, Mumford E, Erlacher-Vindel E, Forcella S, Silk BJ, Ditiu L, El Idrissi A, Raviglione M, Cosivi O, LoBue P, Fujiwara PI. Zoonotic tuberculosis in human 
beings caused by Mycobacterium bovis-a call for action. Lancet Infect Dis 2017;17(1). http://dx.doi.org/10.1016/S1473-3099(16)30139-6.

9. Rebuma F, Rea T, Alehegne W, et al.High Prevalence of Bovine Tuberculosis in Dairy Cattle in Central Ethiopia: Implications for the Dairy Industry and Public Health. PLoS One. 2012; 7(12): e52851.

10. Grange JM.Mycobacterium bovis infection in human beings. Tuberculosis (Edinb). 2001;81: 71-77.

11. de la Rua-Domenech R. Human Mycobacterium bovis infection in the United Kingdom: Incidence, risks, control measures and review of the zoonotic aspects of bovine tuberculosis. Tuberculosis (Edinb). 2001; 86: 77-109.

12. Grange JM, Daborn C, Cosivi O. HIV-related tuberculosis due to Mycobacterium bovis. Eur Respir J. 1994; 7 : 1564-1566.

13. Cosivi O, Grange JM, Daborn CJ, et al. Zoonotic tuberculosis due to Mycobacterium bovis in developing countries. Emerg Infect Dis. 1999;4: 59-70.

14. Al-Thwani AN, Al-Mashhadani MS. Tuberculosis in slaughtered cattle and workers in some abattoirs of Baghdad governorate. Int J Mycobacteriol. 2016;5:S250-S251. https://doi.org/10.1016/j.ijmyco.2016.09.069.

15. Thoen CO, LoBue PA, I de Kantor. Why has zoonotic tuberculosis not received much attention.Int J Tuberc Lung Dis. 2010;14(9):1073-1074.

16. Klein EJ, Boster DR, Stapp JR, et al. Humans as source of Mycobacterium tuberculosis infection in cattle, Spain. Emerg Infect Dis. 2011;17(12):2393-2395.

17. Thoen CO, Steele JH, Kaneene JB. Zoonotic tuberculosis Mycobacterium bovis and other pathogenic Mycobacteria. Mycobacterium bovis infection and control in China. Wiley Blackwell. 2014.

18. Hezekiah KA, Victor O A, Mutolib AS. Knowledge and practices about zoonotic tuberculosis prevention and associated determinants amongst livestock workers in Nigeria; 2015. PLoS One. 2018; 13(6): e0198810.

19. Springer B, Erik C. BÖttger, Philip Kirschner, et al. Phylogeny of the Mycobacterium chelonae-like organism based on partial sequencing of the 16S r RNA Gene and Proposal of Mycobacterium mucogenicum sp. nov. Int J Syst Bacteriol. 1995;45(2):262-7.

20. Kim H, Kim SH, Shim TS, et al. Differentiation of Mycobacterium species by analysis of the heatshock protein 65 gene(hsp65). Int J syst Evol Microbiol. 2005;55(Pt 4):1649-56.

21. Slany M, Svobodova J, Ettlova A, et al. Mycobacterium arupense among the isolates of nontuberculous mycobacteria from human, animal and environmental samples. 2010;55(8):369-376.

22. Mc Corry TP, CM McCormick, MS Hughes, et al. Mycobacterium nonchromogenicum in nasal mucus from cattle in a herd infected with bovine tuberculosis. Vet Microb. 2004;99:281-285.

23. Sawai T, Inoue Y, Doi S, et al. A case of Mycobacterium nonchromogenicum pulmonary infection showing multiple nodular shadows in an immunocompetent patient. Diagn Microbiol Infect Dis. 2006;54(4):311-314. 
24. Lai CC, Chen HW, Liu WL, et al. Fatal Meningitis Caused by Mycobacterium nonchromogenicum in a Patient with Nasopharyngeal Carcinoma. Clinical Infectious Diseases. 2008;46(2):325-326.

25. Kazda J , Cooney R, Monaghan M, et al. Mycobacterium hiberniae sp. nov. IntJ Syst EvolMicr. 1993; 43:352-357.

26. Cloud JL, Meyer JJ, Pounder JI, et al. Mycobacterium arupense sp. nov., a non-chromogenic bacterium isolated from clinical specimens. Int J Syst Evol Microbiol. 2006;56: 1413-1418.

27. Slany M, Pavlik I. Molecular detection of nontuberculous mycobacteria: advantages and limits of a broad-range sequencing approach. J Mol Microbiol Biotechnol. 2012;22(4):268-76.

\section{Tables}

Table 1.The species and strains obtained from the PPD-positive cows.

\begin{tabular}{cc}
\hline NTM species identified & Number of strains \\
\hline Mycobacterium nonchromogenicum & 18 \\
Mycobacterium hiberniae & 1 \\
Mycobacterium arupense & 1 \\
Mycobacterium chitae & 1 \\
\hline
\end{tabular}

Table 2. Distribution of antimicrobial susceptibility of the isolates. 


\begin{tabular}{|c|c|c|c|c|c|}
\hline \multirow[t]{2}{*}{$\begin{array}{l}\text { Antimicrobial } \\
\text { agent }\end{array}$} & \multirow{2}{*}{$\begin{array}{l}\text { Drug } \\
\text { concentration } \\
\text { range }(\mu \mathrm{g} / \mathrm{ml})\end{array}$} & \multicolumn{2}{|c|}{$\begin{array}{l}\text { The } 18 \text { isolates of } M \text {. } \\
\text { nonchromogenicum }\end{array}$} & \multirow{2}{*}{$\begin{array}{l}\text { MIC }(\mu \mathrm{g} / \mathrm{ml}) \text { of the } \\
\text { isolate of } M \text {. } \\
\text { hiberniae }\end{array}$} & \multirow[t]{2}{*}{$\begin{array}{l}\text { MIC }(\mu \mathrm{g} / \mathrm{ml}) \text { of the } \\
\text { isolate of } M \text {. chitae }\end{array}$} \\
\hline & & $\mathrm{MIC}_{50}(\mu \mathrm{g} / \mathrm{ml})$ & $\begin{array}{l}\mathrm{MIC}_{90} \\
(\mu \mathrm{g} / \mathrm{ml})\end{array}$ & & \\
\hline $\begin{array}{l}\text { moxifloxacin } \\
(\mathrm{MOX})\end{array}$ & $0.0625-64$ & 2 & 4 & 2 & $<0.0625$ \\
\hline $\begin{array}{l}\text { gatifloxacin } \\
\text { (GAT) }\end{array}$ & $0.0625-64$ & 4 & 4 & 4 & $<0.0625$ \\
\hline tigecycline (TIG) & $0.0625-64$ & $>64$ & $>64$ & 32 & $<0.0625$ \\
\hline $\begin{array}{l}\text { clofazimine } \\
\text { (CFM) }\end{array}$ & $0.03125-32$ & $>32$ & $>32$ & $>32$ & $<0.0625$ \\
\hline cefoxitin (CFX) & $0.25-256$ & 64 & $>256$ & $>256$ & $<0.0625$ \\
\hline $\begin{array}{l}\text { vancomycin } \\
\text { (VCM) }\end{array}$ & $0.25-256$ & $>256$ & $>256$ & $>256$ & $<0.0625$ \\
\hline $\begin{array}{l}\text { streptomycin } \\
\text { (SM) }\end{array}$ & $0.0625-64$ & 8 & $>64$ & 8 & $<0.0625$ \\
\hline amikacin (AMK) & $0.0625-64$ & 16 & 64 & 16 & $<0.0625$ \\
\hline $\begin{array}{c}\text { azithromycin } \\
\text { (AZM) }\end{array}$ & $0.0625-64$ & $>64$ & $>64$ & $>64$ & 0.125 \\
\hline $\begin{array}{l}\text { sulfamethoxazole } \\
\text { (SMZ) }\end{array}$ & $0.25-256$ & 256 & $>256$ & $>256$ & $<0.25$ \\
\hline rifabutin (RFB) & $0.0625-64$ & 8 & 32 & 32 & $<0.0625$ \\
\hline linezolid (LZD) & $0.0625-64$ & 64 & $>64$ & $>64$ & $<0.0625$ \\
\hline $\begin{array}{l}\text { minocycline } \\
\text { (MIN) }\end{array}$ & $0.25-256$ & 64 & $>256$ & 64 & $<0.25$ \\
\hline $\begin{array}{l}\text { clarithromycin } \\
\text { (CLA) }\end{array}$ & $0.0625-64$ & 16 & $>64$ & $>64$ & $<0.0625$ \\
\hline $\begin{array}{l}\text { meropenem } \\
\text { (MEM) }\end{array}$ & $0.25-256$ & 32 & 64 & 64 & $<0.25$ \\
\hline
\end{tabular}


ethambutol

0.0625-64

1

1

1

$<0.0625$

(EMB)

\begin{tabular}{|c|c|c|c|c|c|}
\hline $\begin{array}{c}\text { capreomycin } \\
\text { (CAP) }\end{array}$ & $0.0625-64$ & 8 & 16 & 4 & $<0.0625$ \\
\hline rifampicin (RIF) & $0.0625-64$ & 32 & 64 & 32 & $<0.0625$ \\
\hline imipenem (IMP) & $0.25-256$ & $>256$ & $>256$ & $>256$ & $<0.25$ \\
\hline $\begin{array}{c}\text { levofloxacin } \\
\text { (LFX) }\end{array}$ & $0.0625-64$ & 8 & 64 & 16 & $<0.0625$ \\
\hline Bedaquiline & 0.015625-16 & $>16$ & $>16$ & $>16$ & $<0.015625$ \\
\hline
\end{tabular}

